http://jmscr.igmpublication.org/home/ ISSN (e)-2347-176x ISSN (p) 2455-0450

crossref DOI: https://dx.doi.org/10.18535/jmscr/v7i7.90

Journal Of Medical Science And Clinical Research

IGM Publication

An Official Publication of IGM Publication

\title{
Causes of Blindness in Applicants for Blindness Certificates Presenting At A Tertiary Centre
}

\section{Authors \\ Dr Tanmay Srivastav, Dr Hemendra Singh, Dr Deepak Mishra, Dr Prashant Bhushan, Prof. M.K.Singh}

Regional Institute of Ophthalmology, Institute of Medical Sciences, BHU, Varanasi, UP

*Corresponding Author

Dr Deepak Mishra

Assistant Professor, Regional Institute of Ophthalmology, IMS, BHU, Varanasi, UP, India

\begin{abstract}
Aim: The aim of this study was to look into the causes of blindness by examination of blind students in a tertiary hospital.

Material and Methods: This was a hospital based cross sectional observational study carried out for a period of two years. A total of 349 patients were included in this study who attended our department for the purpose of demand of writer in their competitive entrance examination. Patients who had visual acuity less than 6/60 to 4/60 in better eye (VI disability percentage 100\%) were included in this study. The subjects with visual acuity greater than 6/60 in better eye, mentally retarded patients and uncooperative patients were excluded. The main cause of blindness was noted according to age and cause. VI disability percentage as proposed by Indian Government was used to give percentage to all subjects. All patients underwent detailed ophthalmic examination including visual acuity, refraction, slit lamp examination and fundus evaluation.

Observations and Results: A total of 349 patients were included in our study out of which 62 percent were males. All of our patients were between 21-30 years. Nystagmus was the most common finding observed in our study in about $166(47.56 \%)$ eyes. Microphthalmos and coloboma along with other globe conditions $(146,41.83 \%)$ were the most common cause of blindness in our patients. Anophthalmos and enophthalmos $(58,16.62 \%)$ was the second most important cause of blindness in this age group. Corneal scarring and opacity $(56,16.05 \%)$ was third in position in ranking list of cause of blindness. Retinal degenerations (30, 8.60\%) and complicated pseudophakia $(28,8.03 \%)$ cases occupied fourth and fifth position repectively among causes of blindness. Optic atrophy (30, 8.59\%) and buphthalmos $(1,0.28 \%)$ was other causes found in contributing to blindness in these subjects.

Conclusion: Childhood blindness remains one of the important causes of visual morbidity in young age individuals. Majority of our cases who came for visual disability certificate suffered from nystagmus and microcornea. Hence children should be treated at the earliest in order to prevent some of the avoidable causes of blindness and allow them to live an acceptable quality of life. Education of parents and society also should be taken into consideration.

Keywords: Blindness, Blind students, Disability Percentage, Visual Impairment.
\end{abstract}

\section{Introduction}

India is second most populated country in world after Republic of China with total population estimated to be around 136.76 crore as of in June 2019 according to data by Ministry of Statistics and Programme Implementation, Government of
India. Blindness since ages has been a foremost problem in Indian health sector. ${ }^{[1-8]}$ Indian subcontinent was first nation to implement an entirely public funded health programme in 1976 under the name of National Programme for Control of Blindness (NPCB). ${ }^{[9]}$ As almost 85- 
$90 \%$ of the total blindness can be cured or prevented, a greater number of blinds in a province symbolizes inefficient ophthalmic services and substandard socioeconomic development. ${ }^{[10]}$ National Health Policy of India emphasized on blindness being an important health concern in 1983 and accordingly target was set to reduce prevalence of blindness from $1.40 \%$ to $0.30 \%$. For many years main emphasis of NPCB was on cataract, but now other diseases like diabetic retinopathy, trauma, strabismus, glaucoma, childhood blindness have also gained attention with joint collaboration of government and private sectors. Recent data suggests that around 12 million blinds reside in India out of 45 million blind populations in entire world. ${ }^{[11]} \mathrm{WHO}$ has estimated increase in blinds to be doubled by the year 2020. Some of the major causes of blindness include cataract, refractive errors, glaucoma, corneal blindness, posterior capsule opacification, vitreo-retinal disorders and others. ${ }^{[12]}$ Around $20 \%$ of visual impairment is contributed by age group 0-49 years. ${ }^{[13]}$ The prevalence of low vision in our country is reported to be around $0.27 \%$ with more prevalence in rural $(0.3 \%)$ than in urban $\operatorname{areas}(0.19 \%)$ as per National Sample Survey Organization in the year 2002. [14] Recent available methods assess visual impairment in elder individuals. There remains paucity of studies on blindness among young individuals between 10 - 50 years of age. ${ }^{[15]}$ Visual problems in young individuals provide a great impact on socioeconomic development. ${ }^{[16]}$ Hence, studies should be done for assessment of burden of blindness in young individuals. Our study aimed to investigate the causes of blindness by examination of blind students who presented for blindness certificate in a tertiary hospital.

\section{Materials and Methods}

This was a hospital based cross sectional observational study carried out for a period of two years from March 2017 to February 2019. A total of 349 patients were included in this study who attended our department applying for blindness certificate and who were entitled for directorate benefits.

Patients who had visual acuity less than 6/60 to $4 / 60$ in better eye (VI disability percentage $100 \%$ ) were included in this study. The subjects with visual acuity greater than $6 / 60$ in better eye, those who suffered from avoidable causes of blindness, one eyed patients, amblyopia, mentally retarded patients and uncooperative patients were excluded.

We analyzed the patients as per Indian government proposed guidelines. (Visual Impairment Disability categories and percentages i.e. category 0-IV, 20-100\%) [Table 1] Patients were considered blind who had best corrected visual acuity less than $6 / 60$ or who had less than 20 degrees field of vision in their better eye. Hence, people in categories II-IV were labeled as blind. The etiology of blindness was also investigated in various age groups. The collected data was tabulated and analyzed statistically using Epi info7 software (CDC, Atlanta, GA).

All patients underwent detailed ophthalmic examination including visual acuity, refraction, slit lamp examination and fundus evaluation.

\section{Observations and Results}

A total of 349 patients were included in our study out of which $217(62.17 \%)$ were males and rest $132(37.83 \%)$ were females. (FIGURE 1)

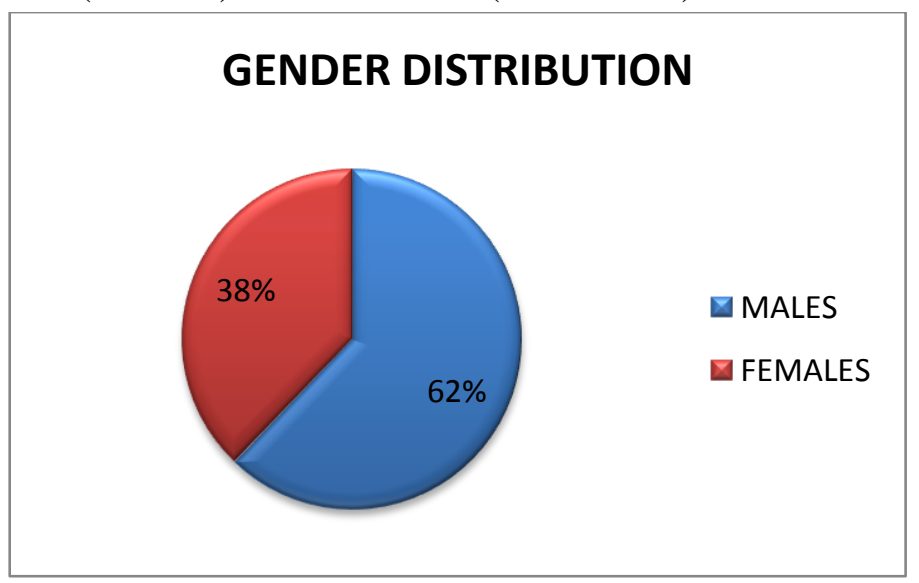

Figure 1: Pie Chart Showing Gender Distribution

As majority of our patients were students, all of our patients were between 21-30 years. Among 
these, majority of them belonged to age group 2526 years $(94,26.93 \%)$ and 23-24 years (86, $24.64 \%)$. Together this constituted about $51.57 \%$ of all patients. 61 patients $(17.47 \%)$ belonged to age group $27-28$ years, $58(16.61 \%)$ belonged to age group 21-22 years and $50(14.32 \%)$ belonged to age group 29-30 years.(Figure 2)

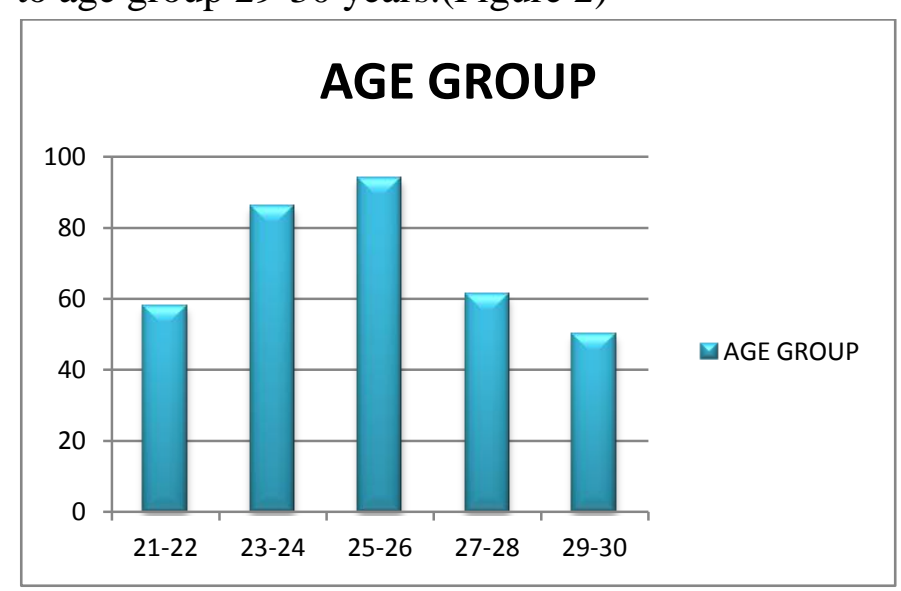

Figure 2: Bar Chart Showing Age Group of Study

Subjects
Nystagmus was the most common finding observed in our study in about 166 (47.56\%) eyes. Microphthalmos and coloboma along with other globe conditions $(146,41.83 \%)$ were the most common cause of blindness in our patients $(p$ value < 0.05). Anophthalmos and enophthalmos $(58,16.62 \%)$ was the second most important cause of blindness in this age group. Corneal scarring and opacity $(56,16.05 \%)$ was third in position in ranking list of cause of blindness. Retinal degenerations (30, 8.60\%) and complicated pseudophakia(28, 8.03\%) cases occupied fourth and fifth position repectively among causes of blindness. Optic atrophy (30, $8.59 \%)$ and buphthalmos $(1,0.28 \%)$ was other causes found in contributing to blindness in these subjects. (Figure 3)

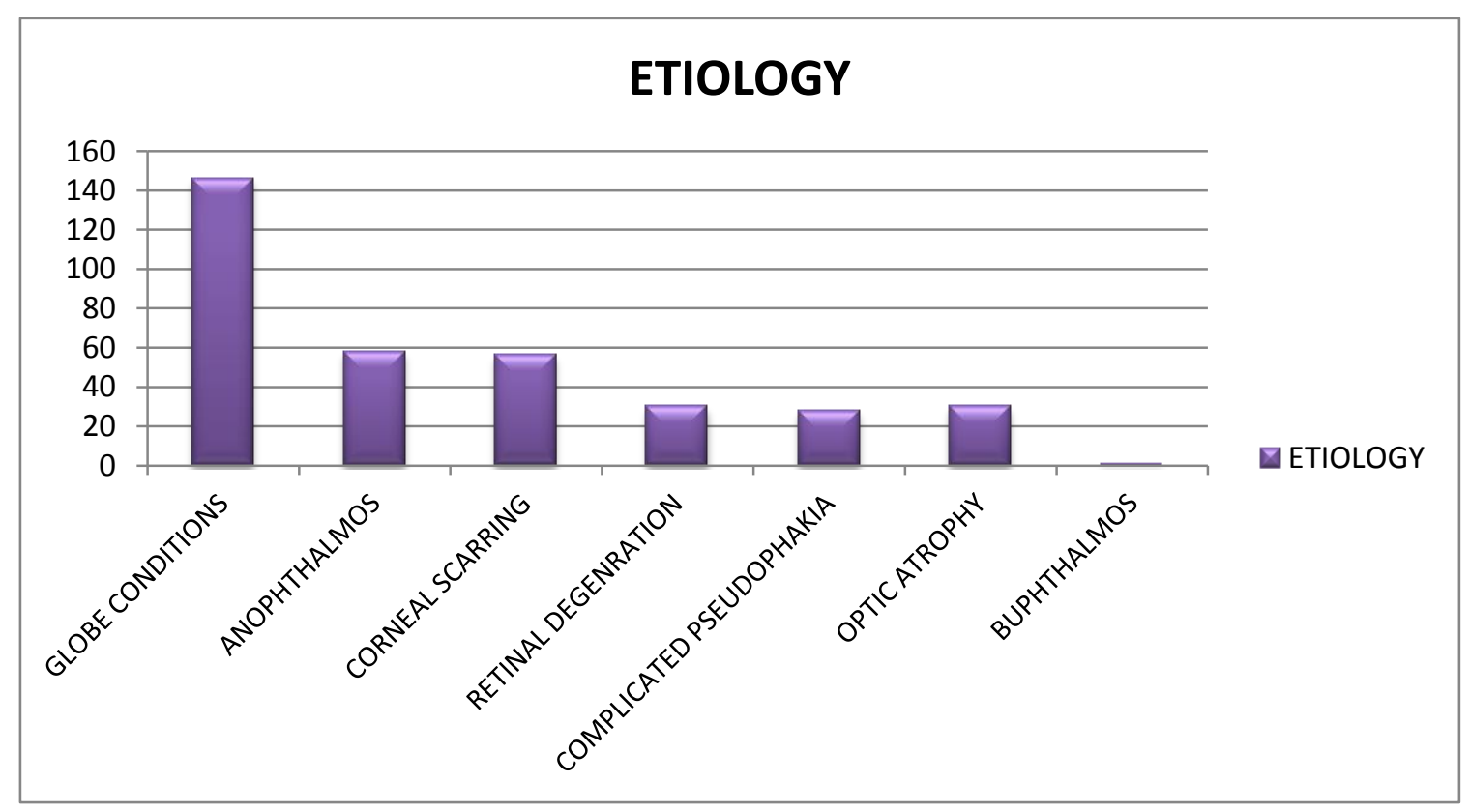

Figure 3: Bar Graph Showing Etiology Of Blindness

\section{Discussion}

There has been increasing trend for application of blindness or disability certificates among blind students. ${ }^{[17]}$ This is because people with blindness certificates get a lot of benefits in our country such as reservation in their competitive examinations and occupations, rebate in income tax, concessions in their travel and other allowances. $^{[18,19]}$ Very few studies have been conducted among students for blindness and their causes.

Majority of our patients were males around $62.17 \%$. This is in accordance with study conducted by Ambastha et al. ${ }^{[20]}$ where they reported a similar finding of male dominance. This can be explained on the basis of their social 
mobility and occupation seeking behavior and hence they require more benefits. ${ }^{[17]}$

The most common etiology of blindness we found in our study was microphthalmos and other globe conditions. This finding was similar to study conducted in Bengal as they also conducted this survey in young patients predominantly. However, Ambastha et al. reported macular scarring to be the most common cause of blindness as they had a larger age group from 0-60 years. We took only young age group patients as they are the major admission seeking group in various colleges and can later on get reservation in government offices and institutions. ${ }^{[17]}$ Hence, appropriate screening program is the need of an hour in order to decrease blindness burden in the society.

Majority of the blindness data is available for either children or for elderly age group i.e. above 50 years. This study was unique in itself as it studied only those students who did apply for blindness disability certificates. In a study conducted by Ambastha et al., macular scarring was reported to be most prevalent cause of blindness in around 20 percent of their patients. ${ }^{[20]}$ This was in contrast to our findings where we found globe conditions such as microphthalmos and chorioretinal coloboma to be most prevalent causes for blindness among student age group.

Dandona et al ${ }^{[21]}$ conducted a survey in population and found post cataract surgery amblyopia to account for $8.31 \%$ of all childhood blindness whereas another study conducted at a school for blind reported complicated pseudophakia to be blindness cause in around $6.61 \%$ of children. ${ }^{[22]} \mathrm{We}$ found complicated pseudophakia in around $8.03 \%$ of our study subjects. Higher incidence of childhood blindness data in our study can be attributed to poor paediatric eye services and poor follow up in parts of Uttar Pradesh and Bihar.Corneal scarring and retinal degeneration has been reported to be major causes that play role in making people blind between age group 31-45 years as this age group is more vulnerable for ocular trauma. ${ }^{[23]}$ among patients greater than 45 years of age, diabetes glaucoma and age related macular degeneration play important role in making people blind worldwide. $^{[24,25]}$

Though our data may not represent whole population, however this surely gives some information about burden of blindness on available ophthalmic health services. Majority of patient donot apply for disability certificates. This fact is proven by a study conducted by Moorfields Eye Hospital in United Kingdom where around half of the patients who were eligible for disability certificate had not applied for it. ${ }^{[25,26]}$ Our study do provide some insight about causes of blindness in young educating age group. Data from blindness certificates can be utilized to plan and implement a more effective and fruitful ophthalmic care services along with data from different population based studies. This data can also be utilized for epidemiological studies to find out region specific etiology and prevalence of blindness.

Table 1: Categories Of Visual Disabilities

\begin{tabular}{|c|c|c|c|}
\hline CATEGORY & BCVA IN BETTER EYE & BCVA IN WORSE EYE & $\begin{array}{l}\text { PERCENTAGE } \\
\text { IMPAIRMENT }\end{array}$ \\
\hline 0 & $6 / 9-6 / 18$ & $6 / 24-6 / 36$ & $20 \%$ \\
\hline I & $6 / 18-6 / 6$ & 6/60-PL & $40 \%$ \\
\hline II & $\begin{array}{l}6 / 60-4 / 60 \text { OR field of } \\
\text { vision } 10 \text { to } 20 \text { degree }\end{array}$ & 3/60-NO PL & $75 \%$ \\
\hline III & $\begin{array}{c}6 / 60-4 / 60 \text { OR field of } \\
\text { vision }<10 \text { degree }\end{array}$ & FC at 1 feet to NO PL & $100 \%$ \\
\hline IV & $\begin{array}{l}\text { FC at } 1 \text { feet to NO PL OR } \\
\text { field of vision }<10 \text { degree }\end{array}$ & $\begin{array}{l}\mathrm{FC} \text { at } 1 \text { feet to NO PL OR } \\
\text { field of vision }<10 \text { degree }\end{array}$ & $100 \%$ \\
\hline One eyed person & $6 / 6$ & FC at 1 feet to NO PL & $30 \%$ \\
\hline Category I-IV & \multicolumn{3}{|c|}{ VISUALLY HANDICAPPED PERSON } \\
\hline
\end{tabular}

FC: Finger counting 


\section{Conclusion}

Childhood blindness remains one of the important causes of visual morbidity in young age individuals. Hence children should be treated at the earliest in order to prevent some of the avoidable causes of blindness and allow them to live an acceptable quality of life. Education of parents and society also should be taken into consideration. Data from blindness applications can provide useful information in order to plan and implement more efficient ophthalmic care services.

\section{References}

1. Dandona L, Dandona R, Naduvilath TJ, et al. Is current eye-care-policy focus almost exclusively on cataract adequate to deal with blindness in India? Lancet 1998;351:312-16.

2. Thulasiraj RD, Nirmalan PK, Ramakrishnan R, et al. Blindness and vision impairment in a rural south Indian population: the Aravind Comprehensive Eye Survey. Ophthalmology 2003;110:1491-8.

3. Dandona L, Dandona R, John RK. Estimation of blindness in India from 2000 through 2020: implications for blindness control policy. Nat Med J India 2001;14:327-34.

4. Thulasiraj RD, Rahamathulla R, Saraswati $A$, et al. The Sivaganga eye survey: I. Blindness and cataract surgery. Ophthalmic Epidemiol 2002;9:299-312.

5. Nirmalan PK, Thulasiraj RD, Maneksha $\mathrm{V}$, et al. A population based eye survey of older adults in Tirunelveli district of south India: blindness, cataract surgery and visual outcomes. $\mathrm{Br} \mathrm{J}$ Ophthalmol 2002;86:505-12.

6. Murthy GVS, GuptaSanjeev, Ellwein LB, et al. A population-based eye survey of older adults in a rural district of Rajasthan. I. Central vision impairment, blindness and cataract surgery.

Ophthalmology 2001;108:679-85.

7. Thylefors B, et al. Global data on blindness. Bull World Health Organ 1995;73:115-21.

8. Limburg H, Vaidyanathan K, Pampattiwar $\mathrm{KN}$. Cataract blindness on the rise? results of a door-to-door examination in Mohadi. Indian J Ophthalmol 1996;44:241-4.

9. Mohan M. National survey of blindnessIndia. NPCB-WHO report. New Delhi: Minsitry of Health and Family Welfare, Government of India, 1989.

10. National programme for control of blindness. Government of Orissa; 2010. Available from: http://www.orissa.gov.in/health_portal/pro gramme/ NPCB/main.html [accessed on 2010 Aug 10]

11. Directorate general of health services. National programme for control of blindness. Chandhigarh: DGHS, Government of Punjab; 2010. Available from: pbhealth.gov.in/pdf/Blindness.pdf [accessed on 2010 Aug 12].

12. Neena J, Rachel J, Praveen V, Murthy GV. Rapid assessment of avoidable blindness in India. PLoSOne 2008;3:e2867.

13. Bourne RRA, Flaxman SR, Braithwaite T, Cicinelli MV, Das A, Jonas JB, et al. Magnitude, temporal trends, and projections of the global prevalence of blindness and distance and near vision impairment: A systematic review and meta-analysis. Lancet Glob Health 2017;5:e888-97.

14. Disabled Persons in India [Internet]. National Sample Survey Organisation, Ministry of Statistics and Programme Implementation Government of India; 2003. Available from: http:// mospi.nic. in/sites/default/fi

les/publication_reports/485_fi nal.pdf. [Last accessed on 2017 Jun 08]. 
15. Marmamula S, Keeffe JE, Rao GN. Rapid assessment methods in eye care: An overview. Indian J Ophthalmol 2012;60:416-22.

16. Frick KD, Gower EW, Kempen JH, Wolff JL. Economic impact of visual impairment and blindness in the United States. Arch Ophthalmol 2007;125:544-50.

17. Ghosh S, Mukhopadhyay S, Sarkar K, Bandyopadhyay M, Maji D, Bhaduri G. Evaluation of registered visually disabled individuals in a district of West Bengal, India.Indian J Community Med 2008;33:168-71.

18. Kumar R. Disability Assessment and Certification Guidelines and Explanations, based on Gazette Notification (Committee under chairmanship of DGHS, GOI) issued by Ministry of Social Justice and Empowerment, GOI, Regd No. DL33004/99 (Extraordinary) Part II, Sec. 1, June 13, 2001.

19. Ministry of Social Justice and Empowerment. Guidelines for evaluation of various disabilities and procedure for certification. Notification dated 1st June, 2001. The Gazette of India extraordinary. Part 1. Section 1. No 154.

20. Ambastha A, Kusumesh R, Sinha S, Sinha BP, Bhasker G. Causes of visual impairment in applications for blindness certificates in a tertiary center of Bihar and its role in health planning. Indian $\mathbf{J}$ Ophthalmol 2019;67(2):204-8.

21. Dandona R, Dandona L. Childhood blindness in India: A population based perspective. $\mathrm{Br} \quad \mathrm{J}$ Ophthalmol 2003;87:263-5.

22. Bhalerao SA, Tandon M, Singh S, Dwivedi S, Kumar S, Rana J. Visual impairment and blindness among the students of blind schools in Allahabad and its vicinity: A causal assessment. Indian J Ophthalmol 2015;63:254-8.
23. Gopinathan U, Fernandes M, Sharma S, Athmanathan S, Rao GN, Garg P. The epidemiological features and laboratory results of fungal keratitis: A 10-year review at a referral eye care center in South India. Indian $\mathrm{J}$ Ophthalmol 2014;62:240-5.

24. Bunce C, Evans J, Fraser S, Wormald R. BD8 certification of visually impaired people. Br J Ophthalmol 1998;82:72-6.

25. Neena J, Rachel J, Praveen V, Murthy GV; Rapid Assessment of avoidable blindness India Study Group. Rapid Assessment of avoidable blindness India study group. PLoS one 2008 ; 6:e 2867.

26. Bunce C, Wormald R. Leading causes of certification for blindness and partial sight in England \& Wales. BMC Public Health 2006;6:58. 